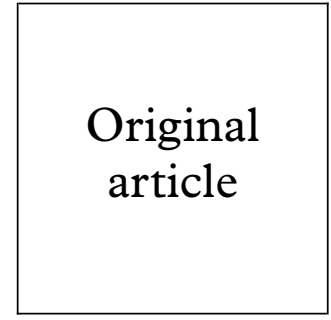

\section{Influence of genital infection on cervical cytology}

\author{
Sarah K Edwards, Chris Sonnex
}

Objective: To ascertain whether the presence of genital infection adversely affects smear quality. Method: A prospective study of all patients having cytology performed. The presence of genital infection was recorded and compared with the smear result.

Results: The presence of genital infection was not associated with inadequate cytology. Inflammatory changes were found in association with symptomatic candidiasis, trichomoniasis, Chlamydia trachomatis infection, primary herpes simplex, and the finding of 21-30 polymorphs per high power field (averaged over 10 fields) on cervical samples. Inadequate cytology was significantly associated with the smear taker.

Conclusion: The presence of genital infection at the time of cytology does not increase the rates of inadequacy, and opportunistic cytology should not be deferred as the patient may default from further appointments.

(Sex Transm Inf 1998;74:271-273)

Keywords: cervical cytology; genital infection

\section{Introduction}

Opportunistic cervical cytology screening is often undertaken in genitourinary medicine clinics, and conventional wisdom dictates that the presence of infection adversely affects the likelihood that the sample taken will be suitable for assessment. As many clinic attenders are presumed to have an infection at the time of their initial presentation, we carried out a prospective study of the results of cytology taken from patients to determine if any association existed.

Department of

Genitourinary

Medicine,

Addenbrooke's

Hospital, Cambridge

CB2 2QQ

$S$ K Edwards

C Sonnex

Correspondence to:

Dr Sarah Edwards,

Department of

Genitourinary Medicine,

Clinic 1a (Box 38)

Addenbrooke's Hospital,

Hills Road, Cambridge

CB2 2QQ.

Accepted for publication 5 March 1998

\section{Method}

We assessed all cytology results undertaken over the period from April 1992 to January 1994 (although no data were collected in May 1992) with the exception of women attending for colposcopy. The following data were recorded for each patient in whom a smear had been taken:

(1) Age at time of smear

(2) Whether they had ever had a smear previously

(3) Result of smear

(4) Staff member taking smear

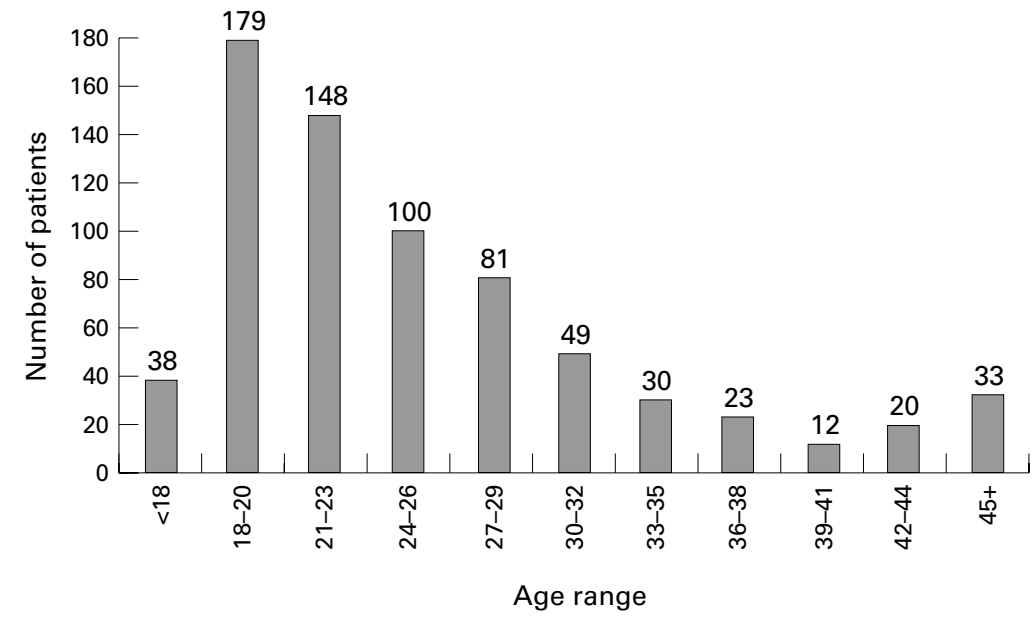

(5) Any infections found at the time that cytology was taken

(6) Whether the patient had current or previous warts, or had a partner with genital warts.

The data were analysed using the Borland database and the Instat statistical package.

\section{Results}

Over the study period 713 smears were taken for which data were collected. Of these patients the reason for taking cytology was "routine" ( $\mathrm{n}$ $=462)$, current warts $(\mathrm{n}=137)$, wart contact $(n=64)$, and past warts $(n=50)$. In 229 cases this was the patient's first smear.

The age distribution is shown in figure 1 .

The majority of smears taken were negative (478 of $713,67 \%$ ) with 118 being inadequate $(16.5 \%)$ (inadequate being defined as unsuitable for analysis). Repeat smears were included from 58 women, of which 42 were repeated because of a previous inadequate sample, six because of an abnormality, and nine because repeats were required by laboratory criteria. Results were only included in the infection analysis if tests were repeated at the time of the repeat cytology. Of these patients 14 had negative tests on both occasions, 28 had different findings, and only five had persistence of the original abnormality.

The results of cytology are shown in table 1 . Reasons for inadequate cytology are shown in table 2.

Table 1 Cytology results

\begin{tabular}{lc}
\hline Result & Number \\
\hline Inadequate & 118 \\
Negative & 478 \\
Inflammatory & 26 \\
HPV infection & 5 \\
HPV + inflammatory & 1 \\
Atypia/?borderline & 6 \\
Borderline & 32 \\
Mild dyskaryosis & 39 \\
Moderate dyskaryosis & 7 \\
Severe dyskaryosis & 1 \\
\hline
\end{tabular}


Table 2 Reasons for inadequate smear

\begin{tabular}{lc}
\hline Reason for inadequate smear & Number (\%) \\
\hline Scanty & $68(58)$ \\
Cytolysed & $12(10)$ \\
Too many bacteria & $3(2.5)$ \\
RBC +++ & $14(12)$ \\
Clumped & $11(9)$ \\
Pus+++ & $10(8.5)$ \\
Distorted cells & $2(2)$ \\
Candida & $4(3.5)$ \\
Insufficient cells & $23(19.5)$ \\
\hline
\end{tabular}

NB: There may be more than one reason for an inadequate smear.

Table 3 Association between inadequate cytology and infection

\begin{tabular}{lccc}
\hline & $\begin{array}{l}\text { Total no of } \\
\text { smears }\end{array}$ & $\begin{array}{l}\text { No } \\
\text { inadequate }\end{array}$ & $\begin{array}{l}\% \\
\text { inadequate }\end{array}$ \\
\hline No infection & 242 & 42 & 17.4 \\
Candida-c & 118 & 21 & 17.8 \\
Candida-s & 87 & 10 & 11.5 \\
BV & 88 & 13 & 14.8 \\
Trichomoniasis & 1 & 0 & 0 \\
Pus +++ & 143 & 22 & 15.4 \\
Pus ++++ & 48 & 7 & 14.6 \\
Chlamydia & 33 & 5 & 15.2 \\
Gonorrhoea & 2 & 0 & 0 \\
Herpes simplex & 15 & 2 & 13.3 \\
Infection present & 411 & 67 & 16.3 \\
\hline
\end{tabular}

Definitions: Pus $+++=$ defined as a mean of $21-30$ polymorphs/high power field (hpf) on assessing 10 fields; Pus $++++=$ defined as $>30$ polymorphs $/ \mathrm{hpf}$ (as above) $\mathrm{BV}=$ bacterial vaginosis; Candida-c=culture only (asymptomatic); Candida-s=symptomatic candidiasis.

NB: There may be more than one infection present.

The commonest reason given for the smear being inadequate was a scanty specimen or insufficient squamous cells. "Too many pus cells" was the reason given for inadequacy in seven of the 29 patients with inadequate cytology and a cervicitis (defined as a mean of $>20$ polymorphs per high power field (hpf) on scanning 10 fields) but was not a cause of inadequate smears in patients with no infection $(0$ of 42) ( $p=0.003$ Fisher's exact test, two tailed).

Data on infections were collected in 653 of the 713 patients. There was no significant difference in the rates of inadequate smears between patients with any specific infection, or between infection and no infection (Fisher's exact test two tailed $p=0.83$ ). The number of inadequate smears compared with infection category is shown in table 3 .

Certain infections were significantly associated with a report of inflammation when compared to samples from patients without infection. Inflammation was reported in nine of 77 patients with symptomatic candidiasis $(\mathrm{p}=0.0002)$; pus +++ on cervical slide (as defined above) 10 of 162 patients $(\mathrm{p}=0.014)$; Chlamydia trachomatis four of 28 patients $(p=0.0005)$; primary herpes simplex two of 13 patients $(p=0.008)$ (Fisher's exact test two tailed $p$ values). In comparison, only two of the 200 patients with adequate cytology and no infection had a report of inflammation. Trichomoniasis was strongly associated with inflammation whereas no association was found with gonorrhoea but this may be due to the small number of cases seen.

Bacterial vaginosis was present in all cases in which unidentified bacteria were seen at cytology.
Table 4 Results of smear by smear taker

\begin{tabular}{lcc}
\hline Smear taker & No of smears & No inadequate (\%) \\
\hline 1 & 78 & $4(5)$ \\
2 & 69 & $8(12)$ \\
3 & 92 & $10(11)$ \\
4 & 168 & $36(21)$ \\
5 & 71 & $20(28)$ \\
6 & 22 & $10(45)$ \\
7 & 44 & $7(16)$ \\
8 & 49 & $6(12)$ \\
9 & 23 & $5(22)$ \\
10 & 97 & $12(12)$ \\
Total & 713 & $118(17)$ \\
\hline
\end{tabular}

A history of past or present warts or contact with warts was associated with the presence of dyskaryosis (when borderline changes are included). In patients with adequate smears, $9.3 \%$ (35 of 375) of those with no history of wart virus exposure had dyskaryosis, compared with $21.7 \%$ (26 of $120, \mathrm{p}=0.0006 \chi^{2}$ with Yates's correction) with current warts, $20 \%$ (nine of $45, \mathrm{p}=0.05$ ) with previous warts, or $27.3 \%$ (15 of $55, \mathrm{p}=0.0003$ ) with a history of contact with warts. There was no significant difference in the numbers of dyskaryotic smears between each of the warts history groups.

The only factor which significantly affected the likelihood of an inadequate smear was the person taking the sample. Nine individuals were involved in smear taking, and smears taken by members of nursing staff were coded as a single smear taker. The numbers of smears taken by each smear taker, and the number of inadequate smears are shown in table 4. Two individuals had a significantly larger number of inadequate samples: $28 \% \mathrm{p}=0.062$, and $45 \%$ $\mathrm{p}=0.013$ respectively, and one person had significantly less inadequate results, 5\% $\mathrm{p}=0.025$ (Fisher's exact test, two tailed).

\section{Discussion}

We have found that the presence of genital infection does not significantly increase the likelihood of inadequate cytology. Opportunistic cervical cytology screening in genitourinary medicine clinics has been advocated previously, ${ }^{1}$ and the purpose of the study was to assess the role of concurrent infection on the adequacy of the cytology sample in order to ascertain the most appropriate time for opportunistic screening. Screening at the patient's first attendance would seem to be the most efficient method, as patients may not be required to reattend, or may fail to return for a further appointment; Ross et al found a 15\% default rate in genitourinary medicine clinic attenders. $^{2}$

Some conditions were associated with an inflammatory result - that is, candidiasis, trichomoniasis, $C$ trachomatis infection, primary herpes, and microscopic cervicitis (as defined above). Previous studies have shown that inflammatory changes are not a reliable indicator for sexually transmitted infections. ${ }^{3} \mathrm{Al}-$ though it has been previously suggested that inflammatory smears are associated with human papilllomavirus infection and bacterial vaginosis, ${ }^{4}$ we were unable to confirm this. These changes did not affect the adequacy of 
the sample. In addition, we also confirmed previous findings ${ }^{5}$ of increased rates of cytological abnormality in women with any history of warts or wart contact.

The only factor significantly associated with an inadequate smear was the staff member taking the sample, as has been found by Holland et $a l,{ }^{6}$ who also found no association with the presence of infection. However, their study was a retrospective survey of inadequate results only and did not contain data on infections for patients with adequate cytology. We were able to identify smear takers with high inadequate rates enabling us to provide further training. We routinely use Aylesbury spatulas, with additional use of a cytobrush as required, since this has been shown to decrease the inadequate rate. ${ }^{7} \mathrm{~A}$ target of less than $10 \%$ inadequacy rate for smears is set as a quality standard and data are provided annually by our cytology laboratory giving inadequate rates by source (unpublished data). Following the start of this study our inadequate rates fell below the $10 \%$ level, as a result of feedback to clinicians and encouraging the use of cytobrushes if the sample was thought likely to be inadequate by spatula alone. Recently the rates have risen coinciding with a change of some clinic staff and further audit is ongoing. We can also compare our proportion of inadequate smears with other local groups performing cytology, which shows our rates to be lower than those of all other referrers except private clinicians (data supplied by our cytology laboratory). However, our inadequate rate is higher than the $5.8 \%$ reported by Holland $e t a l^{6}$ and the reported rate from Leicester ${ }^{8}$ but is comparable with that reported in a recent study from the United States. ${ }^{9}$

In conclusion, patients who have evidence of an infection at the time of cytology have no increase in the rates of inadequacy, and cytology should not be deferred as the patient may default from a further appointment.

Individual contributions from authors not available.

1 Dhar J, Bradley M, Alawettagama AB. Opportunistic cervial cytology screening in a genitourinary medicine depart-

2 Ross JD, McIver A, Blakely A, et al. Why do patients default from follow up at a genitourinary clinic?: a multivariate analysis. Genitourin Med 1995;71:393-5.

3 Dimian C, Nayagam M, Bradbeer C. The association between sexually transmitted diseases and inflammatory cervical cytology. Genitourin Med 1992;68:305-6.

4 Singh V, Gupta MM, Satyanarayana L, et al. Association between reproductive tract infections and cervical inflammatory epithelial changes. Sex Transm Dis 1995;2:25-30

5 Rowen D, Carne CA Sonnex C et al. Increased incidence of cervical cytological abnormalities in women with genital warts: a need for increased vigilance? Genitourin Med 1991; 67:460-3.

6 Holland CR, Smith NA, Barton SE. An audit of inadequate cervical cytology in a genitourinary medicine clinic. Int $\mathcal{f}$ cervical cytology in a gen
STD AIDS 1996; 7:525-7.

7 Boon ME, Alons van Kordelaar JJ, Rietveld Scheffers PE. Consequences of the introduction of combined spatula and Cytobrush sampling for cervical cytology. Improvements in smear quality and detection rates. Acta Cytol 1986;30:26470

8 Young SM, Malet RM. A study comparing cervical cytology results from a genitourinary medicine department with 1993;4:297-9.

Schwebke JR, Zajackowski ME. Effect of concurrent lower genital tract infections on cervical cancer screening. Genitourin Med 1997;73:383-6. 